\title{
Le génome des Papillomavirus, agent probable de cancers et modèle unique de biologie fondamentale
}

La cinquième réunion annuelle "International Workshop on Papillomaviruses" s'est tenue à Cold Spring Harbor (USA) du 3 au 7 septembre dernier. En 1982, la première de ces réunions avait attiré 90 scientifiques fondamentalistes, médecins et chercheurs cliniciens. En 1986, on comptait plus de 300 participants, ce qui illustre le développement de ce champ de recherche, au tout début de cette décennie, à partir des travaux d'un petit nombre de groupes pionniers (Orth, Paris ; Zur Hausen, Heidelberg; Howley, Bethesda). On sait que ces virus présentent un double intérêt, à l'interface médecine/sciences : association avec des carcinomes cutanés et génitaux (cancer du col utérin notamment) évoquant très fortement un rapport causal, particularités uniques de leur fonctionnement au niveau moléculaire qui en font des systèmes modèles eucaryotes très étudiés (maintien d'un provirus non intégré, plasmide), dépendance étroite pour leur multiplication de la différenciation du kératinocyte. Un effort pédagogique réciproque est mené au cours de ces réunions de manière tout à fait exemplaire pour le développement d'une recherche médicale et d'une médecine scientifique. Parmi les résultats présentés, l'extension des données associant certains virus $d u$ groupe, principalement les types 6, 11, 16 et 18 aux carcinomes génitaux ont retenu l'attention sur le plan médical. Les progrès des techniques d'hybridation in situ permettent d'envisager dans un avenir proche la recherche de ces génomes viraux en analyse de routine (un laboratoire spécialisé fonctionne déjà à l'Institut Pasteur). La valeur diagnostique et surtout pronostique de la présence d'un virus donné n'est cependant pas encore complètement établie, faute en particulier de résultats d'études prospectives à long terme: si plusieurs groupes considèrent la présence des types 16 et 18 dans une lésion précoce $\mathrm{m} / \mathrm{s} n^{\circ} 10$ vol. 2, decembre 86 (condylome, carcinomes intraépithéliaux de stades bas) comme l'indication d'un risque plus élevé d'évolution ultérieure rapide, cette notion est encore loin de pouvoir être généralisée. La définition des gènes viraux impliqués et des oncogènes cellulaires activés à chaque étape de progression tumorale progresse. On note ainsi que l'amplification de l'expression de c-myc, initialement observée par Riou et coll. (Villejuif), $n$ 'est pas absolument générale, mais peut être très fréquente aux. stades avancés, au moins dans certaines populations (Gariglio, Mexico).

Sur le plan fondamental, on notera les possibilités ouvertes par l'analyse expérimentale de la transformation par ces virus de tissus humains, greffés dans la capsule rénale de souris nude (Kreider, Hershey), et surtout, les progrès dans l'analyse des mécanismes de régulation de la transcription des gènes viraux, réalisés sur l'un des virus animaux modèles les plus travaillés, celui du papillome bovin (BPV1) (Howley et Lowy, Bethesda). L'un des gènes essentiels pour cette régulation, E2, apparaît en fait responsable, par épissage différentiel (cf. Lexique $\mathrm{m} / \mathrm{s} n^{\circ} 8$, vol. 2, p. 443) de la synthèse de deux protéines régulatrices distinctes. L'une présente une fonction activatrice sur l'activité des promoteurs viraux (cf. Lexique $\mathrm{m} / \mathrm{s} n^{\circ} 2$, vol. 1, p. 105): une telle activité a été décrite pour d'autres protéines, mais l'intérêt du modèle est que la protéine E2 purifiée, s'est révélée capable de reconnaître certaines séquences $d u$ "enhancer", ce qui ouvre la voie à une analyse fine du processus d'activation. Encore plus original apparaît le fait que la seconde protéine fabriquée à partir de ce même gène, une forme tronquée correspondant à la seule région carboxy-terminale, fonctionne, via la reconnaissance des mêmes séquences, comme un répresseur transcriptionnel. L'analyse génétique indiquant d'une part que ce gène codant pour 2 protéines exerce chez BPV1 une (ou des) fonction(s) essentielle(s) pour la transformation tumorale (Di Maio, Yale; Cuzin, Nice), d'autre part que ce mécanisme de régulation est retrouvé chez les Papillomavirus associés à des cancers humains (Yaniv, Paris), on commence à entrevoir comment, dans ce domaine, pourraient se rejoindre recherche fondamentale et cancérologie.

F. C.

\section{BRÈVES Q}

Les trypanosomes, parasites unicellulaires, sont capables de corriger au niveau de l'ARN messager des décalages de phase de lecture ("frameshift") des gènes. Le gène mitochondrial codant chez ces organismes pour la cytochrome oxydase a un décalage de phase au niveau de la position du codon 170 auquel manque une base. Néanmoins ce gène est exprimé et transcrit en un messager parfaitement traductible. La correction du décalage de phase est assurée par l'addition à ce niveau de 4 bases... présentes dans l'ARN et non codées par l'ADN. Cette addition survient probablement lors de la transcription du gène. La "logique " de ce système est pour l'heure impénétrable.

[Benne R et al. Cell 1986; 46 : 819-26.]

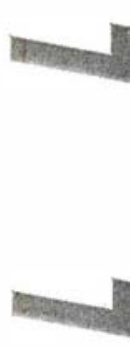

ind
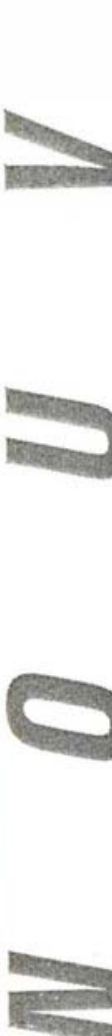